\title{
Sex scent confuses coastal codling moth
}

$\mathrm{P}$ heromone-based mating disruption has emerged as a key alternative to synthetic chemical sprays for codling moth control and is an important part of organic apple management (see special section about organic apple production research beginning on page 20 ).

Pheromone dispensers flood the orchard with the synthetic scent of female codling moths, making it difficult if not impossible for males to follow a scent to a potential mate. It has been likened to trying to find someone in a house of mirrors.

The success of suppressing codling moths with pheromones varies with the production re-

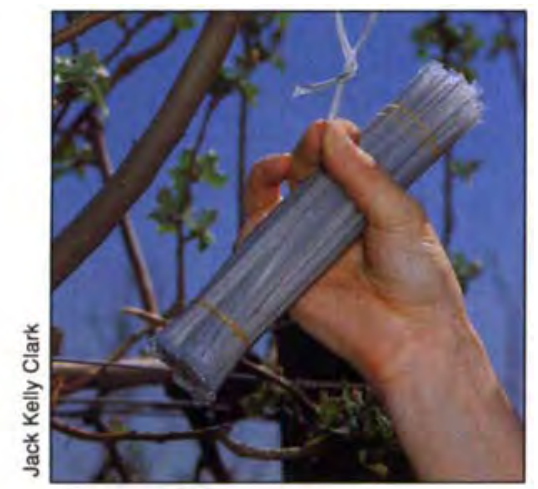
gion, whether populations are established in the area and the level of codling moth pressure. In Kern County, where the climate allows more codling moth generations per season, IPM advisor Walt Bentley has found it often necessary to augment the pheromones with insecticide sprays.

However, results have been more promising in Central Coast orchards. For the past 2 years, entomologist Sean Swezey, UC Santa Cruz, has headed a group of researchers studying the effectiveness of controlling codling moth with pheromonebased mating disruption as part of the statewide organic apple production research funded by USDA's Sustainable Agriculture Research and Education program.

Swezey found that apple growers in low to moderate pressure situations in the

The "rope," or plastic tie, and the membrane are the two formulations of codlemone - the synthetic female sex odor registered for use in California. The pheromone dispensers are placed in the orchard canopy before codling moth emergence. sion. In general, early-maturing varieties including Jonagold and some Red Delicious have benefited from reduced damage due to less susceptibility to late-season egg laying and larval damage in most years.

The integration of mating disruption with supplemental chemical controls for conventional codling moth control programs has also been suggested by observations of conventionally managed "high pressure" situations. A program for this type of orchard would include early insecticide sprays to control the overwintering generation of moths emerging in early spring, and applications of pheromone dispensers and/or subsequent cover sprays as indicated by orchard degree-day model, pheromone trap catches, and early fruit monitoring.

"Our observations suggest that level topography and continuous canopy (especially semidwarf rootstock management) provide the best orchard environment for a successful mating disruption program," Swezey said. "Air volume and pheromone movement models should be devised to explain this observation. Dispenser positioning, generally in the upper canopy, could be validated by an orchard air and pheromone movement model."

The cost of using pheromones ranges between $\$ 80$ and $\$ 120$ per acre per treatment including labor. Swezey has found that most orchards on the Central Coast require two or three treatments per year. Whether the cost is justifiable depends upon the overall objectives of the codling moth management program, he said.

Before considering the pheromone-based mating disruption option, Swezey advises growers to make sure their codling moth monitoring programs are up to date. The requirements for a codling moth mating disruption program include: (1) setting out and monitoring sticky wing-type traps with pheromone lures before bloom (and replacing lures for every adult moth generation); (2) getting the moth "biofix" date (the first date of male flight and $62^{\circ} \mathrm{F}$ sunset temperature); (3) taking daily maximum and minimum temperatures after biofix and making degree-day calculations for monitoring development and predicting flight periods; and (4) making direct, in-season orchard observations of codling moth damage, including an overall postharvest evaluation of total damage caused by codling moth. $-E d$. 